\title{
СРАВНЕНИЕ ОТЕЧЕСТВЕННОГО И ЗАРУБЕЖНОГО ОПЫТА УПРАВЛЕНИЯ ФИНАНСОВОЙ УСТОЙЧИВОСТЬЮ ПРЕДПРИЯТИЯ
}

\section{COMPARISON OF DOMESTIC AND FOREIGN EXPERIENCE IN MANAGING FINANCIAL STABILITY OF AN ENTERPRISE}

\section{N. Fedotova}

Summary: The article deals with the comparison of domestic and foreign experience in managing the financial stability of an enterprise. The main drawback of the existing methods of financial stability of both Russian and foreign authors is that they ignore applied industry features.

Keywords: financial stability, factors affecting financial stability.

\author{
Федотова Надежда Венедиктовна \\ к.э.н., доцент, Российский университет \\ транспорта (МИИТ) \\ nadejda.fedotowa2012@yandex.ru
}

Аннотация: B статье рассматривается сравнение отечественного и зарубежного опыта управления финансовой устойчивости предприятия. Основным недостатком существующих методик уровня финансовой устойчивости как российских, так и иностранных авторов, является игнорирование прикладных отраслевых особенностей.

Ключевые слова: финансовая устойчивость, факторы, влияющие на финансовую устойчивость.
$\mathrm{B}$ настоящее время в большинстве используемых отечественных и зарубежных методик отмечаются определённые отличия в перечне показателей, используемых для определения финансовой устойчивости, и в отдельных методах расчета данных показателей. Помимо этого, исходные данные для проведения расчета показателей, содержащиеся в финансовой отчетности, сформированной по МСФО, несколько отличаются от российской финансовой отчётности, составленной согласно РСБУ, что даже, несмотря на проводимую политику гармонизации законодательства, вызвано существенными различиями в выполнении отдельных учетных операций в процессе финансовой или производственной деятельности. Анализ различных относительных величин и коэффициентов, позволяющих оце- нить финансовую устойчивость, в значительной степени совпадает с анализом отдельных элементов активов и пассивов в зарубежной практике, как это представлено в табл. 1 [1, с.48].

Кроме нескольких аналитических показателей, показывающих зависимость данного предприятия от различных внешних источников средств и представленных в табл.1, в зарубежной практике применяются также различные показатели покрытия процентов по осуществлённым ранее заимствованиям и другие показатели, характеризующие непосредственно сам процесс накапливания и обслуживания долга. Причём, в зарубежном опыте анализ финансовой устойчивости, выполненный совместно с оценкой его рыночной стоимости, являет-

Сравнение отечественных и зарубежных методик оценки относительных величин, характеризующих финансовую устойчивость предприятия

\begin{tabular}{|c|c|c|c|}
\hline \multirow{2}{*}{ Наименование показателя } & \multicolumn{2}{|c|}{ Формула для расчета } & \multirow{2}{*}{ Характеристика } \\
\hline & Отечественный опыт & Зарубежный опыт & \\
\hline $\begin{array}{c}\text { Коэффициент финансовой зависимости } \\
\text { (Total debt ratio) }\end{array}$ & $\begin{array}{c}\text { Всего источников средств / } \\
\text { собственный капитал }\end{array}$ & $\begin{array}{c}\text { Совокупные пассивы / Сово- } \\
\text { купные активы }\end{array}$ & $\begin{array}{l}\text { Характеризует уровень финансиро- } \\
\text { вания активов за счет обязательств }\end{array}$ \\
\hline $\begin{array}{c}\text { Коэффициент финансовой активности } \\
\text { (финансовый рычаг, коэффициент финан- } \\
\text { сового риска) } \\
\text { (Debt equity ratio) }\end{array}$ & $\begin{array}{l}\text { Привлеченные средства / } \\
\text { Капитал и резервы }\end{array}$ & $\begin{array}{l}\text { Общая задолженность / } \\
\text { Капитал и резервы }\end{array}$ & $\begin{array}{c}\text { Характеризует уровень зависи- } \\
\text { мости предприятия от внешних } \\
\text { агентов }\end{array}$ \\
\hline $\begin{array}{c}\text { Коэффициент долгосрочного привле- } \\
\text { чения заемных средств (Longterm debt } \\
\text { ratio) }\end{array}$ & $\begin{array}{l}\text { Долгосрочные обязательства / } \\
\text { Долгосрочные обязательства } \\
\text { + Капитал и резервы }\end{array}$ & $\begin{array}{c}\text { Долгосрочные обязательства } \\
\text { / Долгосрочные обязатель- } \\
\text { ства + Капитал и резервы }\end{array}$ & $\begin{array}{c}\text { Показывает долю привлеченного } \\
\text { капитала в перманентном капитале } \\
\text { предприятия }\end{array}$ \\
\hline
\end{tabular}


ся одним из главных направлений анализа вследствие того, что весьма часто реальная стоимость предприятия существенно меньше его текущей рыночной стоимости. Следует отметить, что высокоразвитый фондовый рынок передовых зарубежных стран даёт возможность искусственного завышения стоимости предприятия за счет гудвила, тогда как у малых и средних отечественных предприятий подобная возможность в большинстве случаев отсутствует.

В зарубежной практике оценка финансовой устойчивости дополняется расчетом и последующей оценкой показателей [1, с.49]:

- доходность акций (индикатор «price earnings ratio»): показывает долю общей чистой прибыли на одну номинированную акцию и определяется делением чистой прибыли на общую численность номинированных акций;

- коэффициент «цена / денежный поток» (индикатор «price / cash flow»): даёт возможность оценить текущую доходность акций в соотношении с денежными потоками исследуемого предприятия в ходе его деятельности;

- коэффициент рыночной цены (индикатор «market to book value»): демонстрирует, до какой степени текущая рыночная цена акций данного предприятия превышает её цену по балансу и рассчитывается как соответствующее соотношение.

Необходимо отметить, что основными недостатками существующих методик диагностики уровня финансовой устойчивости как российских, так и иностранных авторов, является игнорирование прикладных отраслевых особенностей. Например, применение в России некоторыми экономистами различных международных анализов для проведения оценки финансовой устойчивости, неадаптированных к реалиям российской экономики обусловливает принятие неверных управленческих и финансовых решений, применение в низкорентабельной деятельности, и в конечном итоге утверждение финансовой стратегии развития экономического субъекта, которая практически не соответствует текущим реалиям и фактической ситуации в российской экономике.

Рекомендуемая общая последовательность определения типа финансовой устойчивости предприятия в отечественных методиках представлена на рис. 1 [2, с.19]

Согласно представлениям отечественных исследователей, как видно из рис. 1, оценка финансовой устойчи-

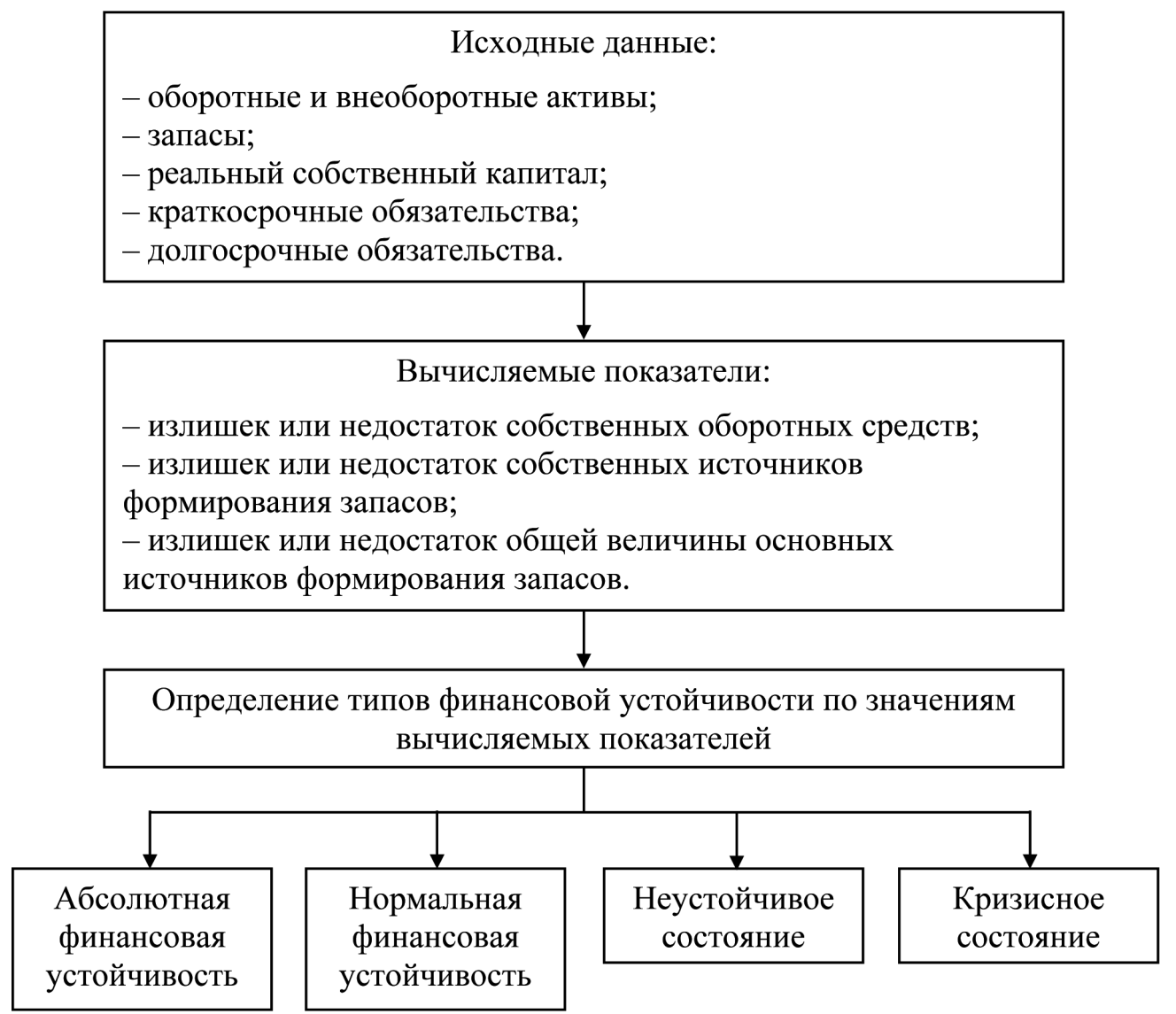

Рис. 1. Рекомендуемая общая последовательнодть определения типа финансовой устойчивости в отечественных методиках 
вости предприятий лежит в основе анализа финансового состояния предприятия, важнейшим направлением развития которого является использование различных экономико-математических методов. Основными задачами, возникающими в процессе анализа и моделирования финансового состояния предприятия, является выбор методов, критериев, показателей и алгоритмов его оценки.

В отечественной аналитической практике для проведения качественного анализа финансовой устойчивости применяются различные методические подходы. Широко известным является анализ сформированной системы абсолютных, относительных или средних аналитических показателей, демонстрирующих уровень финансовой устойчивости. Хотя коэффициентный анализ представляет собой достаточно репрезентативный и эффективный инструмент для организации оценки финансовой устойчивости, однако в ряде случаев использованием традиционных методов анализа не в состоянии представить верную картину финансовой устойчивости.

Например, коэффициентный метод, точно так же как другие аналитические методы, имеет не только очевидные преимущества в виде своей простоты и универсальности, но и некоторые недостатки, к которым следует отнести в том числе и низкий уровень достоверности различных нормативных коэффициентов, так как данные нормативные значения напрямую зависят от экономической отрасли и масштабов экономического субъекта, что зачастую игнорируется. Коэффициентный метод обычно является оптимальным для предприятий, которые специализируются на определённых направлениях деятельности. Прикладное применение данного метода является весьма трудоёмким для больших предприятий, так как для проведения сравнительной оценки даже одного из всей системы коэффициентов требуется использовать множества отраслевых нормативов. Кроме того, на величину и динамику показателей финансовой устойчивости значительно влияет выбранный вариант учётной политики, например, отдельные положения учётной политики касательно метода оплаты отгрузки товаров и продукции непосредственным контрагентам [2, с.19].

Существенным недостатком анализа финансовой устойчивости на базе сформированной системы коэффициентов представляется расчёт данных коэффициентов исключительно на начало или конец установленного периода анализа и оценка выявленных отклонений от установленных нормативных значений, которые отмечались только в определённый момент времени, что не позволяет полностью определить конкретный механизм и факторы данной динамики. Оценка различных коэффициентов финансовой устойчивости только в отдельные моменты отчётного периода времени не способно в полной мере оценить эффективность работы этого предприятия в промежуточные периоды. Вследствие этого фактическое отсутствие промежуточной информации о динамике финансовой устойчивости может повлиять на формирование неверной оценки всей системы показателей финансового состояния исследуемого экономического субъекта.

К главным преимуществам большинства зарубежных методик следует отнести измеримость и репрезентативность их результатов, сопоставимость и определённость в используемом количественном составе коэффициентов и качественной интерпретации полученных результатов. Также можно отметить универсальность и относительную упрощенность данных методик для анализа финан-

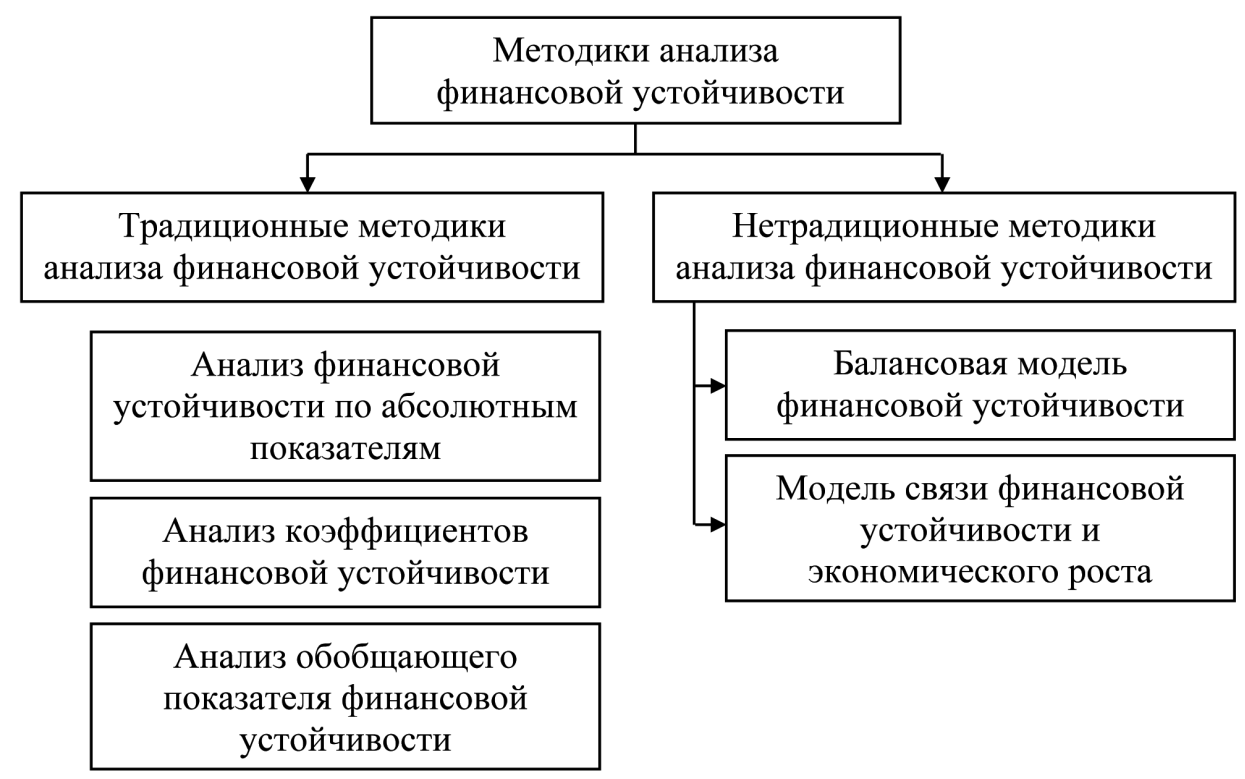

Рис. 2. Выбранные методики анализа финансовой устойчивости 
совой устойчивости. При этом, отечественные методики, напротив, характеризуются существенными отличиями вследствие расхождения точек зрения отдельных авторов методик, что выражается в различных системах показателей для оценки того или иного явления. Таким образом, можно предположить, что отечественные методики, используемые для оценки финансовой устойчивости, также требует некоторой унификации и сообразного уменьшения численности применяемых анализируемых показателей. В ходе этого следует отдавать наибольшее предпочтение анализу и расчёту системы коэффициентов финансовой устойчивости, которые в прикладной деятельности продемонстрировали наибольшую содержательность, сопоставимость и необходимость для финансового аналитика [1, с.50].

Выбранные методики анализа финансовой устойчивости, которые могут быть использованы для проведения анализа представлены на рис. 2.

Можно предположить, что использование всех представленных на рис.2 методик, используемых для проведения расширенного анализа финансовой устойчивости, позволит наиболее полно и с необходимой степенью точности охарактеризовать текущее состояние и динамику финансовой устойчивости.

В целом, по результатам рассмотрения основных положений российских и зарубежных методик, используемых в ходе оценки финансовой устойчивости, можно заключить, что независимо от особенностей разных стран, анализ финансовой устойчивости должен демонстрировать возможности предприятия в части финансирования своей деятельности на основе использования собственных средств. Зарубежные методики отличаются преимущественно тем, что в них основной упор делается на оценку особенностей обслуживания долга и работу на фондовом рынке, тогда как в отечественных методиках делается акцент прежде всего на оценку достаточности собственных источников. Также результаты данного анализа применяются при разработке управленческих решений о привлечении на предприятие дополнительных ресурсов и оценки способности погасить сформированные обязательства за счет использования активов различной степени ликвидности. После проведения оценки финансовой устойчивости и формулирования выводов о её уровне, выйти из неустойчивого положения предприятие может путем своевременного пополнения запасов и дальнейшей оптимизации их структуры, а также на основе обоснованного уменьшения уровня запасов.

ЛИТЕРАТУРА

1. Балакин М.Ф., Люшина Э.Ю. Методические аспекты оценки финансовой устойчивости предприятия. // Управление экономическим системами. 2012. № 12, C. 48-55.

2. Рыжков К.А. Оценка финансового состояния организации. // Аудит и налогообложение. 2013. № 11, С.18-24.

3. Федотова Н.В. Сущность и факторы финансовой устойчивости предприятия. // Транспортное дело России. 2017. № 3. С. 29-30.

4. Федотова Н.В. Анализ финансовой устойчивости компании. // Транспортное дело России. № 1. С. 13-17.

○ Федотова Надежда Венедиктовна (nadejda.fedotowa2012@yandex.ru).

Журнал «Современная наука: актуальные проблемы теории и практики» 